\title{
Genotoxicity studies of benzofuran dioxetanes and epoxides with isolated DNA, bacteria and mammalian cells
}

\author{
Waldemar Adama ${ }^{a}$, Michael Ahrweiler ${ }^{\mathrm{a}}$, Chantu R. Saha-Möller ${ }^{\mathrm{a}}$, \\ Markus Sauter ${ }^{\mathrm{a}}$, André Schönberger ${ }^{\mathrm{a}}$, Bernd Epe ${ }^{\mathrm{b}}$, Elvira Müller ${ }^{\mathrm{b}}$, \\ Dietmar Schiffmann ${ }^{b}$, Helga Stopper ${ }^{b}$ and Dieter Wild ${ }^{b}$ \\ "Institut für Organische Chemie and 'Institut für Toxikologie, Universität Würzburg, Würzburg (Germany') \\ Key words: 1,2-Dioxetane; Benzofuran dioxetane; Benzofuran epoxide; DNA damage; Mutagenicity; \\ ${ }^{32}$ P-postlabelling; DNA adduct; Repair endonuclease; FPG protein; 8-Hydroxyguanine
}

\section{SUMMARY}

1,2-Dioxetanes, very reactive and high energy molecules, are involved as labile intermediates in dioxygenase-activated aerobic metabolism and in physiological processes. Various toxicological tests reveal that dioxetanes are indeed genotoxic. In supercoiled DNA of bacteriophage PM2 they induce endonucleasesensitive sites, most of them are FPG protein-sensitive base modifications (8-hydroxyguanine, formamidopyrimidines). Pyrimidine dimers and sites of base loss (AP sites) which were probed by UV endonuclease and exonuclease III are minor lesions in this system. While the alkyl-substituted dioxetanes do not show any significant mutagenic activity in different Salmonella typhimurium strains, heteroarene dioxetanes such as benzofuran and furocoumarin dioxetanes are strongly mutagenic in $S$. typhimurium strain TA100. DNA adducts formed with an intermediary alkylating agent appear to be responsible for the mutagenic activity of benzofuran dioxetane. We assume that the benzofuran epoxides, generated in situ from benzofuran dioxetanes by deoxygenation are the ultimate mutagens of the latter, since benzofuran epoxides are highly mutagenic in the $S$. typhimurium strain TA100 and they form DNA adducts, as detected by the ${ }^{32} \mathrm{P}$ postlabelling technique. Our results imply that the type of DNA damage promoted by dioxetanes is dependent on the structural feature of dioxetanes. Furthermore, the direct photochemical DNA damage by energy transfer, i.e., pyrimidine dimers, plays a minor role in the genotoxicity of dioxetanes. Instead, photooxidation dominates in isolated DNA, while radical damage and alkylation prevail in the cellular system.

Correspondence to: Prof. Dr. W. Adam. Institut für Organische Chemie, Universität Würzburg, Am Hubland, D-8700 Würzburg, Germany. 


\section{INTRODUCTION}

There is convincing evidence that 1,2-dioxetanes are involved in enzymatic oxidation processes [1]. For example, they were postulated as labile intermediates in the dioxygenase-activated aerobic metabolism of arenes. In particular, arenes, such as benzene [2] and naphthalene [3,4], and heteroarenes, such as benzofuran [5], are aerobically metabolized by the microorganism Pseudomonas putida to the corresponding cis-dihydrodiols and presumably proceeds through dioxetane intermediates. In the case of benzene [2], it was demonstrated by ${ }^{18} \mathrm{O}$-labelled experiments that a dioxetane is indeed a plausible intermediate in this microbial oxidation [2] (Eqn. 1), since both oxygen atoms are derived from the same dioxygen molecule and the cis

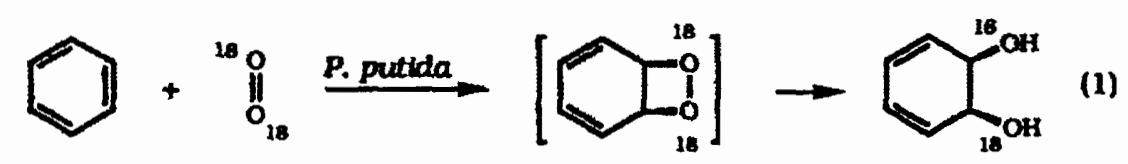

configurated vicinal diol product excludes the popular [6] arene oxide mechanism as possible alternative. Moreover, the fact that chemiluminescence was observed in the reaction of 7,8-dihydroxy-7,8-dihydrobenzo[a]pyrene with microsomal cytochrome P-450 suggests that a dioxetane intermediate is also involved in this enzymatic oxidation [7]. Another indication is the biological function of plasmalogens [8], for which it was postulated that they protect animal cell membranes from singlet oxygen and other aggressive oxygen species by forming plasmalogen dioxetanes. Finally, the involvement of dioxetanes in spontaneous mutations [9] and oxidative stress [10] has been proposed.

In view of the quite general potential significance of dioxetanes in oxidative metabolism and other physiological processes, it is of relevance to elucidate the genotoxic activity of these highly reactive cyclic peroxides. Indeed, extensive investigations on the genotoxicity of 1,2-dioxetanes have shown that they induce different types of DNA lesions [11]. Thus, in cell-free calf thymus DNA, 3,3,4-trimethyl-1,2-dioxetane (TrMD) leads to pyrimidine dimers [12,13]. On the other hand, in supercoiled DNA of bacteriophage PM2 alkyl-substituted dioxetanes (1a-d) induce predominantely

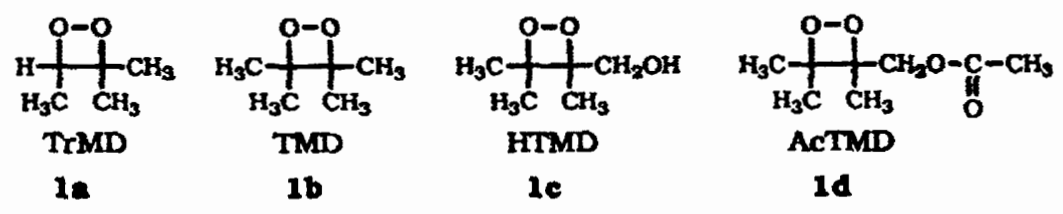

endonuclease-sensitive base modifications, but relatively few single strand breaks and sites of base loss (AP sites) [11,14]. However, only a small fraction of the base modifications consisted of pyrimidine dimers, as established by employing a specific UV endonuclease preparation from Micrococcus luteus [14]. Most recent results [15] reveal that the majority of the dioxetane-promoted endonuclease-sensitive base modifi- 
cations in PM2 DNA are recognized by FPG protein (formamidopyrimidine-DNA glycosylase). Since the FPG protein recognizes both the 7,8-dihydro-8-oxoguanine (8-oxoGua) and formamidopyrimidines (Fapy), these are presumably the major DNA lesions responsible for the observed DNA damage. Furthermore, the lesions caused by dioxetanes in PM2 DNA do not resemble those caused by direct $\mathrm{UV}^{260}$ irradiation. Instead, they appear to be akin to the modifications caused by singlet oxygen $[11,15]$.
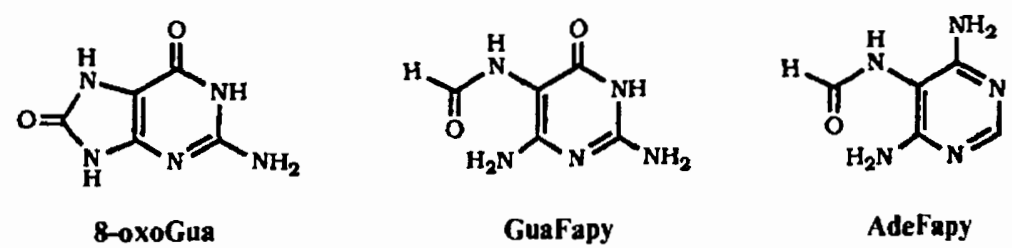

Not only isolated but also cellular and bacterial DNA is damaged by dioxetanes. For example, dioxetanes cause single strand breaks in human leukemia cells (HL 60) and in Syrian hamster embryo (SHE) fibroblasts $[11,16]$, in the latter micronuclei were also produced [16]. In Escherichia coli dose-dependent induction of the SOS function sfia was observed [17].

On the other hand, although alkyl-substituted 1,2-dioxetanes are genotoxic, they do not exhibit any significant mutagenic activity in several $S$. typhimurium strains in the Ames test. Nonetheless, recently we have observed that heteroaromatic dioxetanes such as those from benzofurans 2 [18] and furocoumarins 3 [19] are strongly mutagenic in the $S$. typhimurium strain TA100. In spite of the fact that dioxetanes are effective agents to perform photobiology in the dark [1], the mutagenic damage in-

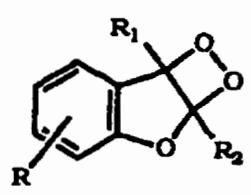

2

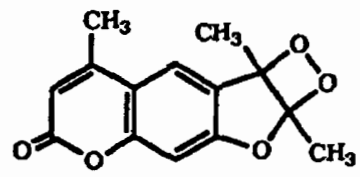

3

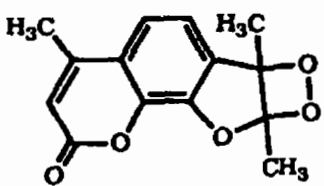

sb

duced by benzofuran dioxetanes in the $S$. typhimurium strain TA100 could not be photoreactivated [11], which implies that the DNA lesions are not pyrimidine dimers.

During the last few years we have investigated the mechanism of the mutagenicity of benzofuran dioxetanes and related compounds by employing toxicological and chemical methods. Our preliminary results $[20,21]$ suggest that alkylation of DNA is mainly responsible for the strong mutagenic activity of benzofuran dioxetanes. Here we summarize the results of our toxicological investigations and chemical model studies on the mutagenesis induced by benzofuran dioxetanes.

\section{PREPARATION OF BENZOFURAN DIOXETANES AND EPOXIDES}

The benzofuran dioxetanes 2, which were employed for the genotoxic investigations described herein, were synthesized by photooxygenation of the corresponding 
benzofurans [18]. The furocoumarin dioxetanes $3 \mathbf{a}, \mathbf{b}$ were also accessible by this method. Most of these dioxetanes are stable enough to be handled at ambient temperature. In contrast, the benzofuran epoxides 4 are very labile and these hitherto unknown compounds were prepared for the first time by deoxygenation of the corresponding dioxetanes with stoichiometric amounts of dimethyl or diphenyl sulfide at $-30^{\circ} \mathrm{C}[21]$. An alternative and more direct route to benzofuran epoxides is the epoxidation of benzofurans by dimethyldioxirane [22].

\section{MUTAGENICITY OF BENZOFURAN DIOXETANES AND EPOXIDES (AMES TEST)}

A large number of benzofuran dioxetanes 2 were assayed for mutagenicity in the $S$. typhimurium strain TA100, which is mutable mainly by alkylating agents and $\mathrm{UV}^{260}$ radiation. Specific mutagenic activities of selected benzofuran dioxetanes are given in Table I; the experimental details of the assay have been published elsewhere [18]. Evidently, several benzofuran dioxetanes are strongly mutagenic. Dioxetanes with dimethyl substitution on the furan ring $\left(\mathrm{R}^{1}, \mathrm{R}^{2}=\mathrm{CH}_{3}\right.$ in structure 2$)$ and electronaccepting groups on the benzo ring (cf. structure $2 \mathrm{a}$ in Table I) are most mutagenic [18]. Since dioxetanes serve as efficient chemical source of triplet-excited carbonyl compounds [1] and the $S$. typhimurium strain TA100 is sensitive to photochemical damage, it was expected that the lesions induced by benzofuran dioxetanes would be of photochemical origin. However, the DNA lesions in S. typhimurium strain TA100 could not be photoreactivated [11]. This observation suggests that the DNA damage responsible for the mutations is not typical photochemical damage, i.e., pyrimidine dimers. In view of the fact that the S. typhimurium strain TA100 is also mutable by the action of alkylating agents, we suspect that an intermediate with a high alkylating propensity, generated in situ from the benzofuran dioxetanes, is responsible for the observed mutagenicity.

Since benzofuran dioxetanes 2 can be deoxygenated by L-methionine [21] to the epoxides $\mathbf{4}$ and these epoxides are very potent alkylating agents (see chemical model studies), we assume that the benzofuran epoxides are the ultimate mutagens of the benzofuran dioxetanes. To substantiate this hypothesis, several authentic benzofuran epoxides, whose corresponding dioxetanes are mutagenic, were assayed for mutagenic activity in $S$. typhimurium strain TAl00 under the same conditions employed for dioxetanes [18]. The specific mutagenicities of selected epoxides are given in Table I. Indeed, benzofuran epoxides are effective mutagens. The structure-activity relationship is found to be similar to that of the benzofuran dioxetanes. An electron-accepting functionality such as an acetyl group in the benzo ring enhances the mutagenic activity of both benzofuran epoxide and dioxetane significantly (cf. Table I). The much lower effect of the 2,3-dimethylbenzofuran epoxide (4b) compared to that of the corresponding dioxetane $\mathbf{2 b}$ may arise from substantial hydrolysis and thermal decomposition of this epoxide under the conditions of the mutagenicity assay. 


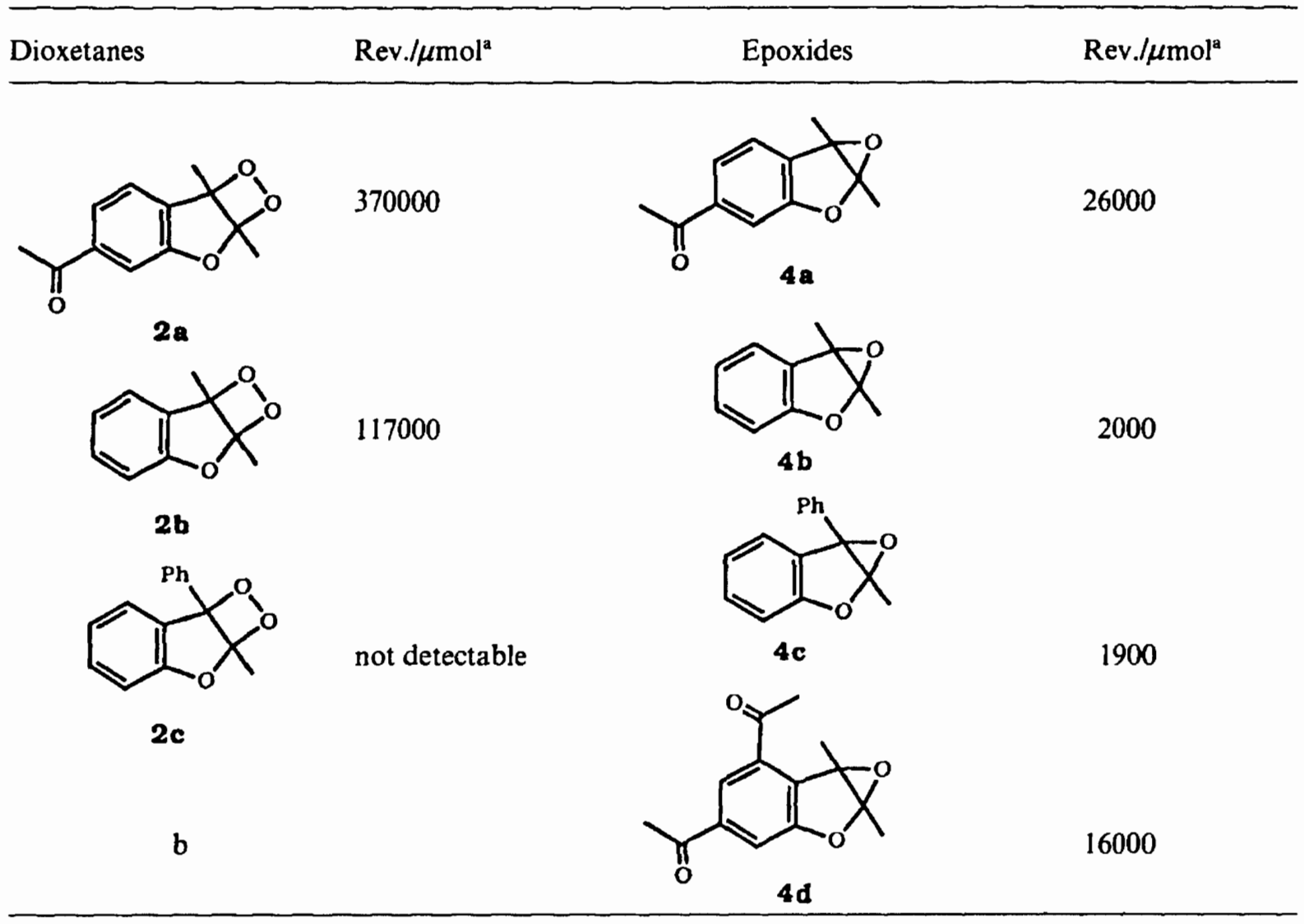

‘ Specific mutagenic activities calculated by linear regression analysis from the dose-response curve [17,20]; standard deviations are approx. $10 \%$ and the spontaneous revertant frequencies per plate 150-200.

${ }^{b}$ The corresponding dioxetane of the epoxide $\mathbf{4 d}$ is not known.

\section{CHEMICAL MODEL STUDIES}

To elucidate the molecular nature of the DNA damage responsible for the mutagenicity of benzofuran dioxetanes and epoxides, their reaction with nucleophiles was investigated [21]. The chemical transformations are displayed in Scheme I. Benzofuran dioxetanes can be efficiently deoxygenated by sulfides under very mild conditions to the corresponding epoxides and they are far more reactive than the dioxetanes. Nucleophiles such as alcohols, thiols, and imidazole afford the respective adducts even at $-78^{\circ} \mathrm{C}$ in very high yield. In contrast, the benzofuran dioxetanes require acid catalysis and significantly higher reaction temperature to form adducts with such nucleophiles. For example, the 2,3-dimethylbenzofuran epoxide (4b) suffers rapid hydrolysis at subambient temperature, whereas the corresponding dioxetane $\mathbf{2 b}$ reacted with water only in the presence of trifluoroacetic acid as catalyst. This might be 

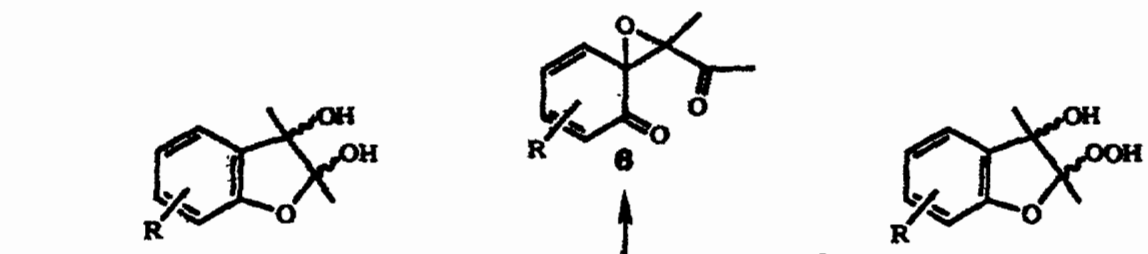<smiles>[R]c1ccc(C(C)=NO)c(O)c1</smiles>

$\frac{\mathrm{H}^{+} / \mathrm{NaN}_{3}}{5^{\circ} \mathrm{C} \cdot 11 \mathrm{~h}}$
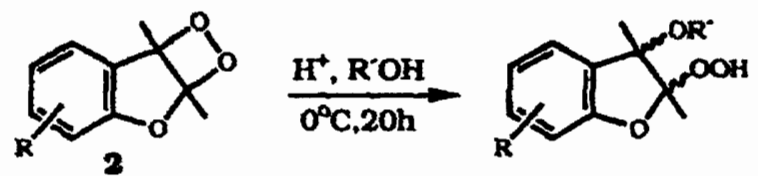<smiles>[R]c1cc2c3c(c1)-c1nccn1[C@@]3(C)[C@@](C)(O)O2</smiles>

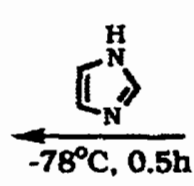

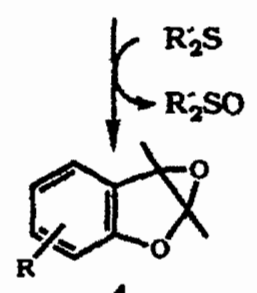<smiles>[R20][R6]([H])(C)O[SbH2]</smiles><smiles>[R]c1ccc2c(c1)O[C@](C)(O)[C@@]2(C)O</smiles><smiles>[R]c1ccc2c(c1)OC(C)(O)[C@]2(C)Sc1ccccc1</smiles><smiles>[R]C1C=CC(=C(C)C(C)=O)C(=O)C1</smiles>

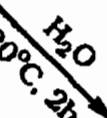<smiles>[R]c1ccc2c(c1)OC(C)(O)[C@]2(C)O</smiles>

Scheme 1. Chemical transformations of benzofuran dioxetanes and epoxides with nucleophiles.

the reason for the much lower mutagenic activity of epoxide $4 \mathbf{b}$, in comparison with that of dioxetane $\mathbf{2 b}$.

Remarkable is the valence isomerization of benzofuran epoxides 4 to their corresponding quinone methides 5 . This isomerisation is analogous to that postulated for the furan epoxides into enediones [23]. Depending on the substituent of the benzo ring, either the epoxide or the quinone methide is formed [22]. For example, electronacceptors favor the epoxide, while electron donors favor the quinone methide tautomer. It is of interest to note that this parallels the observed structure-activity relationship observed in the Ames test for both the benzofuran epoxides and dioxetanes. Whether this correspondence relates to the epoxide vs. quinone methide tautomerism needs yet to be experimentally verified.

A similar rearrangement is also observed for the benzofuran dioxetanes, which affords the corresponding spiroepoxides 6 . This isomerization takes place thermally in competition with the fragmentation of the dioxetane ring [11]; however, it is efficiently catalyzed by bromide ion and the spiroepoxide is formed quantitatively. In contrast to the epoxide-quinone methide tautomerism, the dioxetane-spiroepoxide isomerization is irreversible. 
DETECTION OF DNA ADDUCTS OF BENZOFURAN DIOXETANES AND EPOXIDES BY ${ }^{32}$ P-POSTLABELLING

The chemical model studies with benzofuran dioxetanes and epoxides and the mutagenicity tests suggest that alkylation of DNA, which leads to adducts, plays an important role in the mutagenesis induced by these substances. To confirm alkylation of the DNA by the mutagenic benzofuran epoxides and their corresponding dioxetanes, the ${ }^{32} \mathrm{P}$-postlabelling method [24] was employed. This technique is a convenient and sensitive tool for the detection of DNA adducts, with the additional advantage that no radioactively labelled DNA alkylating agents are required.

The ${ }^{32} \mathrm{P}$-postlabelling assays were performed according to the following procedure: After incubation of calf thymus DNA $(1 \mathrm{mg} / \mathrm{ml})$ with benzofuran epoxide or dioxetane (final concentration $20 \mathrm{mM}$ ) at $37^{\circ} \mathrm{C}$ for $1 \mathrm{~h}$, the unreacted material was removed by triple extraction with diethyl ether. The DNA was isolated by precipitation with ethanol. Since in the standard ${ }^{32} \mathrm{P}$-postlabelling procedure no or only very weak adduct spots could be observed after autoradiography, the nuclease P1 modification was performed according to literature $[25,26]$. Each sample was labelled with 80-100 $\mathrm{mCi}$ of $\left[{ }^{32} \mathrm{P}\right] \mathrm{ATP}$ (specific activity $3000 \mathrm{Ci} / \mathrm{mmol}$ ). The ${ }^{32} \mathrm{P}$-labelled adduct bisphosphates were applied to a PEI-cellulose plate and the chromatographic separation was carried out as described elsewhere [27], with the exception that the urea concentration for the D3 run was reduced to $4.5 \mathrm{M}$ to decrease the mobility of the adducts. The DNA adducts were located by autoradiography on a Kodak XAR-5 film with intensifying screen at $-70^{\circ} \mathrm{C}$.

When calf thymus DNA was treated with benzofuran epoxides 4a,b (Table I), up to three main and several minor adducts were detected, as shown in Figure la for benzofuran epoxide 4b. Adducts were also detected with 6-acetylbenzofuran epoxide 4a. The autoradiogram is comparable with that of the benzofuran epoxide $4 \mathbf{b}$; this correspondence is presumably due to analogous chemical reactions of both epoxides with DNA. For epoxide $4 \mathrm{~b}$ the dose dependence on the extent of DNA modification was tested and confirmed in the range of 10 to $50 \mathrm{mM}$ (data not shown); at higher concen-
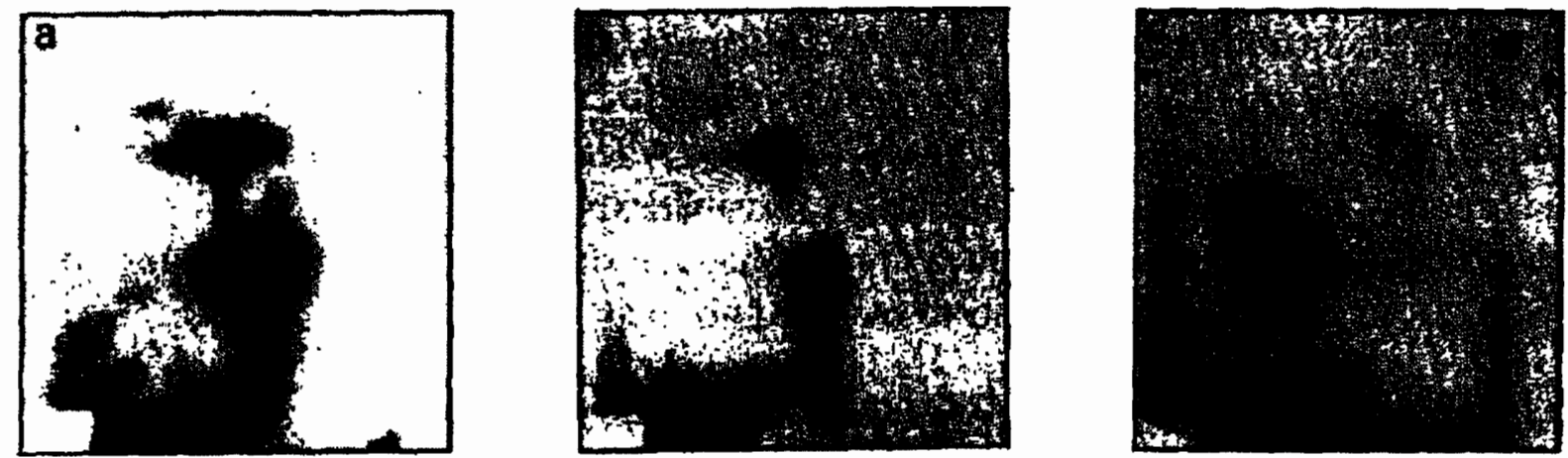

Fig. 1. Autoradiograms of 4-D PEI-cellulose maps of ${ }^{32} \mathrm{P}$-labelled digests of calf thymus DNA treated with benzofuran epoxide $4 \mathrm{~b}(20 \mathrm{mM})$ (a); benzofuran dioxetane $2 \mathrm{~b}(20 \mathrm{mM})$ in the presence of L-methionine $(40 \mathrm{mM})(\mathrm{b})$; and benzofuran dioxetane $2 \mathrm{~b}(20 \mathrm{mM})(\mathrm{c})$. 
trations (> $50 \mathrm{mM}$ ) the adduct level remained constant. The total amount of DNA adducts formed with the highly reactive epoxide $4 \mathrm{~b}$ was found to be only approx. one adduct in $10^{6}$ nucleotides. Presumably efficient hydrolysis of the benzofuran epoxide is responsible for the observed low DNA adduct frequency. However, the real adduct frequency could be significantly higher in view of the fact that adduct recovery and labelling efficiency was not determined because authentic standards of benzofuran epoxide adducts are until now not available. It should also be mentioned that small aromatic adducts, i.e., polar adducts which contain only one aromatic ring, are often not retained in the DI run, which may result in significant loss of adducts under the chromatographic conditions employed. In addition, some adducts may undergo further reaction (e.g., imidazole ring opening, depurination, etc.), which would escape detection in the ${ }^{32} \mathrm{P}$-postlabelling assay. Furthermore, some adducts might be sensitive to the nuclease P1 treatment and lost through dephosphorylation.

In order to identify which DNA bases were modified by benzofuran epoxide $\mathbf{4 b}$, the four $3^{\prime}-\mathrm{dNps}$ were examined independently. Several adducts were observed with $3^{\prime}$ $\mathrm{dGp}$ and $3^{\prime}$-dAp and one single adduct with $3^{\prime}$-dCp. No adducts with $3^{\prime}-\mathrm{dTp}$ could be detected. In view of the fact that benzofuran epoxides can be generated in situ by deoxygenation of the corresponding benzofuran dioxetanes with L-methionine, we investigated adduct formation with in situ deoxygenated benzofuran dioxetane. A DNA solution $(1 \mathrm{mg} / \mathrm{ml})$ which was $40 \mathrm{mM}$ in l-methionine was treated with benzofuran dioxetanes $\mathbf{2 a , b}$ (final concentration $20 \mathrm{mM}$ ). In both cases DNA adducts could be detected by the nuclease P1 method (autoradiogram for 2b shown in Fig. 1b). These adducts are chromatographically similar to those of the benzofuran epoxide $\mathbf{4 b}$ (Fig. 1a), which implies that benzofuran epoxide type DNA adducts are formed when benzofuran dioxetanes are treated with methionine. As control experiment, the benzofuran dioxetanes $\mathbf{2 a , b}$ were treated with calf thymus DNA without the deoxygenating agent methionine. Benzofuran dioxetane $2 \mathrm{~b}$ produced two adducts, as detected by the nuclease P1 method (Fig. 1c). Several adducts were formed with 6-acetylbenzofuran dioxetane $2 \mathbf{a}$.

The different chromatographic behavior of the adducts of benzofuran dioxetane and epoxide (Fig. la and c) suggests that they are structurally distinct. In view of the pronounced difference in their chemical reactivity (Scheme I), adduct formation with benzofuran dioxetane is unexpected. We anticipated alkylation for the epoxides $\mathbf{4}$ and oxidative base modifications by oxygen transfer for the dioxetanes 2 . These results require further chemical investigations to assess whether benzofuran dioxetanes can act directly as DNA alkylating agents. A possible explanation is provided by the fact that dioxetanes can react with nucleophiles through substitution at the peroxide bond $\left(\mathrm{S}_{\mathrm{N}} 2\right.$ reactivity) and thereby lead to oxidized adducts [28].

\section{GENOTOXICITY IN SUPERCOILED DNA FROM BACTERIOPHAGE PM2}

As already mentioned, dioxetanes induce DNA damage in supercoiled DNA from bacteriophage PM2. They cause mainly base modifications, which were detected by 
a crude repair endonuclease preparation from $M$. luteus. Only few single strand breaks and AP sites were observed and a relatively small fraction of the $M$. luteussensitive base modifications were found to be pyrimidine dimers; however, the majority of endonuclease-sensitive modifications were unidentified [11]. In order to obtain structural information of these unknown dioxetane-induced base modifications, the dioxetane-treated PM2 DNA was assayed by using two specific repair endonucleases from $E$. coli, viz. endonuclease III, which recognizes 5,6-dihydropyrimidines [29], and formamidopyrimidine-DNA glycosylase (FPG protein), which detects formamidopyrimidines [30] and 7,8-dihydro-8-oxoguanine (8-hydroxyguanine) [31,32]. The quanti-

TABLE II

DIOXETANE INDUCED DNA LESIONS IN PM2 DNA

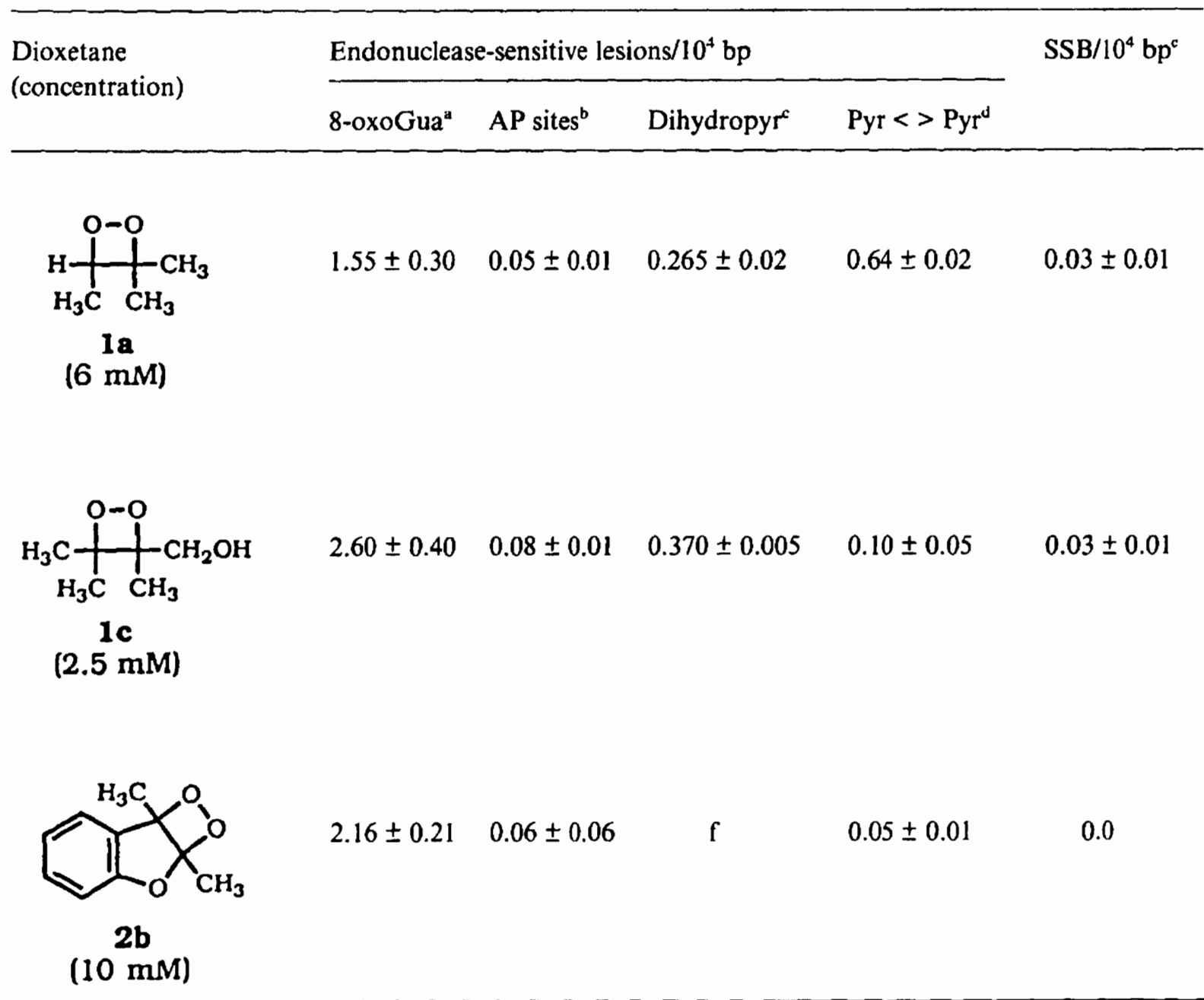

\footnotetext{
${ }^{2}$ Base modifications detected by FPG protein; some of these lesions could be formamidopyrimidines or other unknown modifications sensitive to this enzyme.

${ }^{b}$ Modifications detected by exonuclease III from $E$. coli.

' Base modifications detected by endonuclease III.

${ }^{d}$ Base modifications detected by the photodimer-specific enzyme from $M$. luteus (UV endonuclease).

' Single strand breaks [33].

${ }^{\mathrm{r}}$ Not determined.
} 


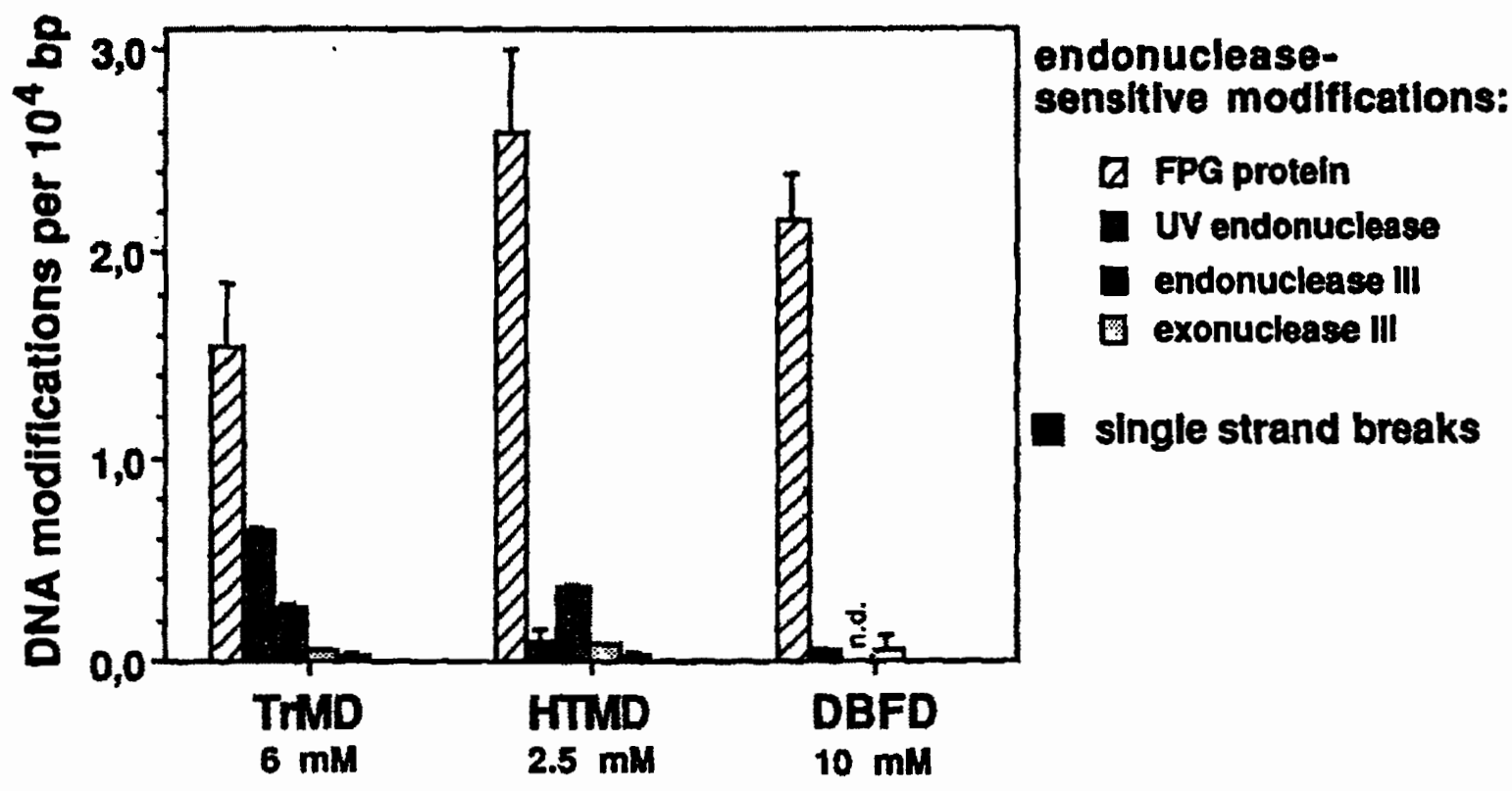

Fig. 2. Damage profiles caused by the dioxetanes TrMD, HTMD and DBFD in PM2 DNA.

tative results are presented in Table II and the DNA damage profiles for the alkylsubstituted dioxetanes 1a,c and the benzofuran dioxetane $\mathbf{2 b}$ are shown in Figure 2. The damage profiles for alkyl-substituted dioxetane HTMD and benzofuran dioxetane DBFD are very similar; however, both differ from that of trimethyldioxetane TrMD, for which a much higher relative amount of pyrimidine dimers was found. In all cases a relatively small number of modifications is sensitive to endonuclease III and exonuclease III, which reveals that both dihydropyrimidines and AP sites are minor lesions. On the other hand, a large number of FGP protein-sensitive lesions were observed. These unexpected results imply that the most prominent endonuclease-sensitive base modifications caused by dioxetanes are mainly 8-hydroxyguanine and formamidopyrimidines, provided that no other unknown base modifications are recognized by the FPG protein. Of these modifications, only the 8-hydroxyguanine was identified by comparison of HPLC retention times of the excised bases with that of the authentic material (data not shown).

\section{GENOTOXICITY IN SHE CELLS}

Benzofuran dioxetane $\mathbf{2 b}$ generates micronuclei in SHE cells to a much higher extent ( $2680 \pm 390$ micronuclei per 2000 cells $/ \mathrm{mM}$ ) than previously observed [11] for alkyl-substituted dioxetanes such as HTMD (400 \pm 5 micronuclei per 2000 cells/ $\mathrm{mM}$ ). Since an analysis for the presence of kinetochores (CREST antibody staining) provides information about the mechanism of micronucleus formation, such a kinetochore analysis was performed on the benzofuran dioxetane (2b)-induced micronuclei by following the published procedure [34]. The results are given in Table III and are compared with those of some known genotoxic agents. About $40 \%$ of the micronuclei 
caused by the benzofuran dioxetane responded positive to CREST antibody staining. On the other hand, 4-nitroquinoline- $\mathrm{N}$-oxide (4-NQO), a highly genotoxic agent which causes structural aberrations of chromosomes, generated only approx. 6\% CREST serum positive micronuclei $\left(\mathrm{CRMN}^{+}\right)$, while E-diethylstilbestrol (DES), a nonmutagenic carcinogen which causes mitotic disturbances and aneuploidy [34], produced $85 \% \mathrm{CRMN}^{+}$. These results indicate that 2,3-dimethylbenzofuran dioxetane (2b) causes not only DNA damage but also interferes with chromosome distribution in mitosis.

\section{CONCLUDING REMARKS}

1,2-Dioxetanes are involved in dioxygenase activated aerobic metabolisms and in physiological processes. The elucidation of genotoxic potentials of dioxetanes and the identification and characterization of DNA lesions elicited by these reactive peroxides is of general significance for the mechanistic understanding of carcinogenesis and mutagenesis in oxidative metabolism at the molecular level.

It has been shown herein by various genotoxicity tests that dioxetanes are potent

TABLE III

KINETOCHORE ANALYSIS OF MICRONUCLEI INDUCED IN SHE CELLS

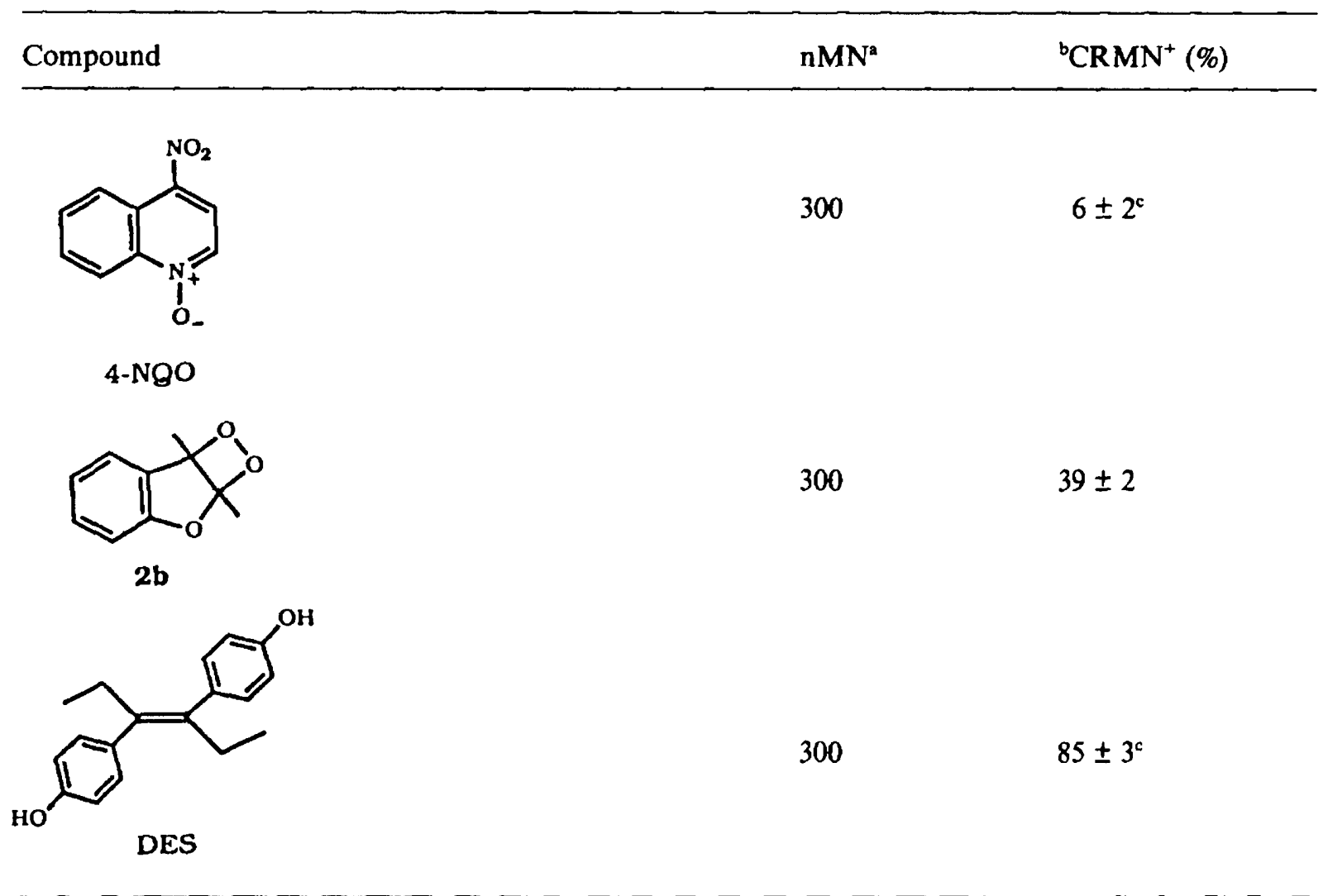

\footnotetext{
${ }^{a}$ Number of micronuclei examined for the presence of kinetochores.

${ }^{b}$ Number of micronuclei which responded positive to CREST serum.

${ }^{\mathrm{c}}$ Literature values [34].
} 


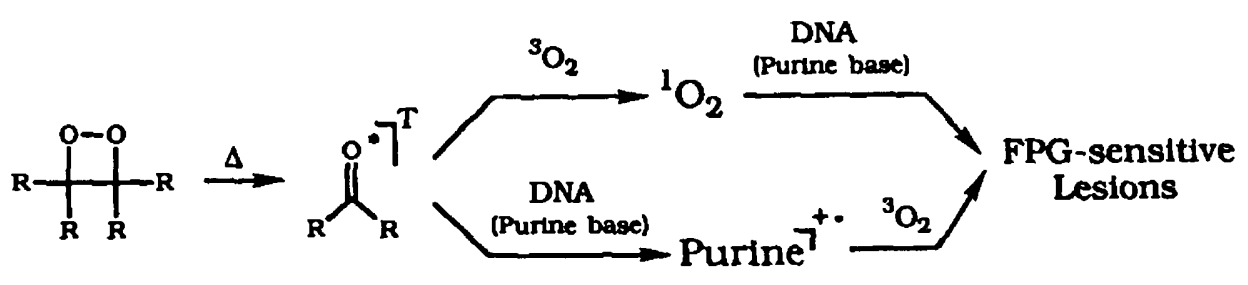

Scheme II. Formation of FPG-sensitive lesions by thermal decomposition of dioxetane.

genotoxic agents, which promote different types of lesions in cell-free, bacterial and cellular DNA. The type of DNA damage induced by dioxetanes is dependent on the structural feature of dioxetanes and is different in cellular and cell-free systems. For example, while the alkyl-substituted dioxetanes 1 do not show any significant mutagenic activity in various $S$. typhimurium strains, the heteroarene dioxetanes such as benzofuran 2 and furocoumarin 3 dioxetanes are highly mutagenic in S. typhimurium strain TA100. On the other hand, several alkyl-substituted dioxetanes 1 caused in mammalian cells (HL 60) mainly single strand breaks (ssb), whereas in isolated DNA (PM2 DNA) they formed predominantly endonuclease-sensitive sites but very few single strand breaks. In contrast to alkyl-substituted dioxetanes 1, benzofuran dioxetane $\mathbf{2 b}$ does not induce any detectable pyrimidine dimers in PM2 DNA.

The endonuclease-sensitive sites generated by dioxetanes in supercoiled PM2 DNA constitute mainly base modifications sensitive to FPG protein; pyrimidine dimers and AP sites are minor lesions in this system. Since FPG protein recognizes formamidopyrimidines and 8-hydroxyguanine, the dioxetane-induced DNA damage in the cell-free system is likely to consist mainly of these two base modifications. However, other unknown FPG protein-sensitive base modifications cannot be excluded so far. Recently it has been demonstrated that 8-hydroxyguanine is formed in the reaction of singlet oxygen with DNA [35] and with mononucleosides [36]. The fact that a 2-fold increase of the dioxetane-induced FPG-sensitive base modifications was observed in $\mathrm{D}_{2} \mathrm{O}$ vs. $\mathrm{H}_{2} \mathrm{O}$ as solvent [15], indicates that singlet oxygen plays a certain role in the formation of FPG protein-sensitive lesions, but is not a mandatory intermediate; otherwise a much higher $\mathrm{D}_{2} \mathrm{O}$ effect would have been observed.

With respect to our present results on dioxetanes, a novel pathway may operate, in which FPG protein-sensitive base modifications are generated from triplet-excited carbonyl products (derived from the thermal decomposition of dioxetanes) both directly through electron transfer and indirectly by singlet oxygen (Scheme II). While in the first case a purine radical cation is a likely intermediate, it remains to be established whether singlet oxygen also reacts through electron transfer or whether it forms a purine endoperoxide which acts as a precursor of 8-hydroxyguanine and formamidopyrimidines. The base modifications induced by dioxetanes in isolated DNA presumably result from electronically excited carbonyl products.

On the other hand, heteroarene dioxetanes such as the benzofuran dioxetanes $\mathbf{2}$ are the first known dioxetanes with strong mutagenic activity in $S$. typhimurium strain TA100. The mutagenic DNA lesions promoted by benzofuran dioxetanes $\mathbf{2}$ are not 


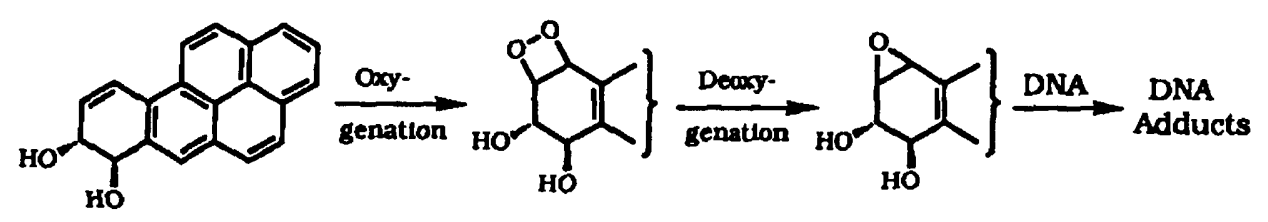

Scheme III. DNA damaging pathway of arenes and heteroarenes.

pyrimidine dimers. Rather, DNA adducts formed with an intermediary alkylating agent, the latter generated in situ from dioxetanes by deoxygenation, appear to be responsible for the mutations induced in the Salmonella strain. In view of the fact that benzofuran dioxetanes 2 can be deoxygenated quantitatively to the corresponding benzofuran epoxides 4 by L-methionine, it is plausible that the benzofuran epoxides 4 are the ultimate mutagens of benzofuran dioxetanes. Support for this hypothesis derives from the confirmation that the benzofuran epoxides 4 are also strong mutagens in the $S$. typhimurium strain TA100 and that they form DNA adducts, as detected by the ${ }^{32}$ P-postlabelling technique.

We propose that the novel mutagenesis mechanism, i.e., deoxygenation of the benzofuran dioxetanes 2 to the highly reactive epoxides $\mathbf{4}$ as ultimate mutagens (Scheme III), may be of general scope. This is to say, genotoxic arenes and heteroarenes may be transformed into their reactive epoxides by deoxygenation of the corresponding dioxetanes, the latter are generated as labile intermediates in the dioxygenase-activated aerobic metabolism.

On the basis of our results on the toxicological investigations with 1,2-dioxetanes presented here, we conclude that pyrimidine dimers, which can be generated by energy transfer from triplet-excited carbonyl products to pyrimidine bases and subsequent photodimerization of the latter, play a minor role in the genotoxicity of dioxetanes. Instead, photooxidation dominates in cell-free DNA, while radical damage in mammalian cells and alkylation in bacterial DNA prevail (Scheme IV).

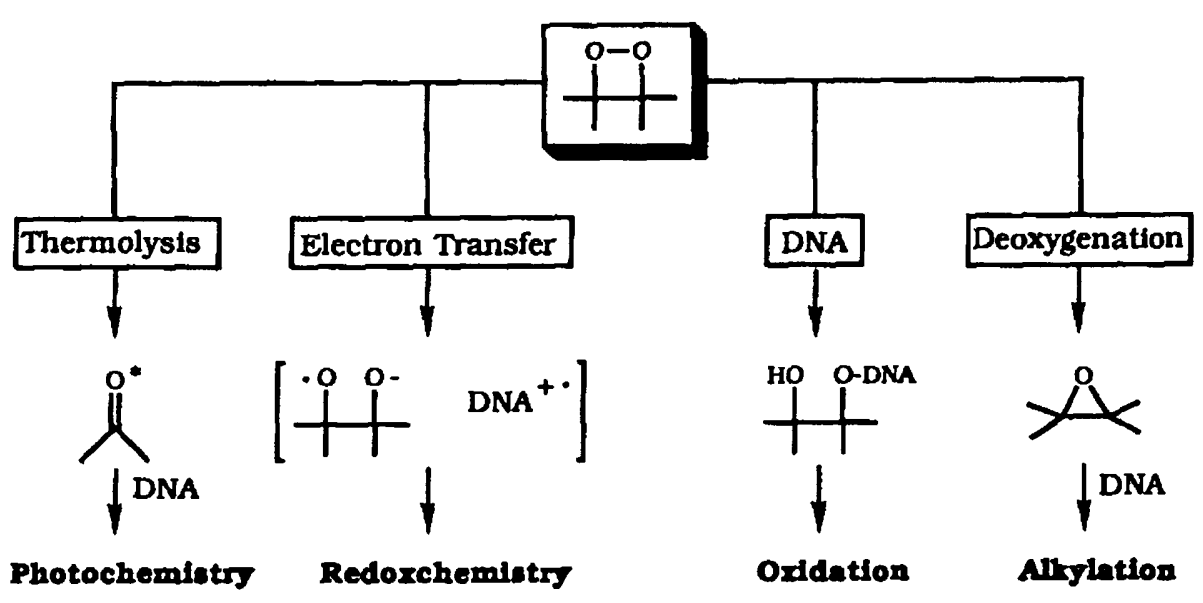

Scheme IV. Different pathways of DNA damage by dioxetane. 


\section{ACKNOWLEDGEMENTS}

We thank the Deutsche Forschungsgemeinschaft (Sonderforschungsbereich 172), the Wilhelm-Sander-Stiftung, and the Sponsors of the International Symposium of the Sonderforschungsbereich 172, Würzburg, June 18-20, 1992 for generous financial support.

\section{REFERENCES}

1 Cilento, G. and Adam, W. (1988) Photochemistry and photobiology without light. Photochem. Photobiol, 48, 361-368.

2 Gibson, D.T., Cardini, G.E., Maseles, F.C. and Kallio, R.E. (1978) Incorporation of oxygen-18 into benzene by Pseudomonas putida. Biochemistry 9, 1631-1635.

3 Jerina, D.M., Daly, J.W., Jeffrey, A.M. and Gibson, D.T. (1971) cis-1,2-Dihydroxy-1,2-dihydronaphthalene: a bacterial metabolite from naphthalene. Arch. Biochem. Biophys. 142, 394-396.

4 Deluca, M.E. and Hudlicky, T. (1990) Microbial oxydation of naphthalene derivatives. Absolute configuration of metabolites. Tetrahedron Lett. 31, 13-16.

5 Boyd, D.R., Sharma, N.D., Boyle, R., Austin, R., McMordie, S., Chima, J. and Dalton, H. (1992) A 'H-NMR method for the determination of enantiomeric excess and absolute configuration of cisdihydrodiol metabolites of polycyclic arenes and heteroarenes. Tetrahedron Lett. 33, 1241-1244.

6 Gibson, D.T. (1984) Microbial Degradation of Organic Compounds, Microbiology Series, Vol. 13, Marcel Dekker, New York.

7 Thompson, A., Biggley, W.H., Posner, G.H., Lever, J.R. and Seliger, H.H. (1986) Microsomal chemiluminescence of benzo[a]pyrene-7,8-dihydrodiol and its synthetic analogues trans- and cis-1-methoxyvinylpyrene. Biochim. Biophys. Acta 882, 210-219.

8 Morand, O.H., Zoeller, R.A. and Raetz, R.H. (1988) Disappearance of plasmalogens from membranes of animal cells subjected to photosensitized oxidation. J. Biol. Chem. 263, 11597-11606.

9 Smith, K.C. and Sargentini, N.J. (1985) Metabolically-produced 'UV-like' DNA damage and its role in spontaneous mutagenesis. Photochem. Photobiol. 42, 801-803.

10 Sies, H. (1986) Biochemie des oxidativen stress. Angew. Chem. 98, 1061-1075.

11 Adam, W., Beinhauer, A., Mosandl, T., Saha-Möller, C., Vargas, F., Epe, B., Müller, E., Schiffmann, D. and Wild, D. (1990) Photobiological studies with dioxetanes in isolated DNA, bacteria, and mammalian celts. Environ. Health Perspect. 88, 89-97.

12 Lamola, A.A. (1971) Production of pyrimidine dimers in DNA in the dark. Biochem. Biophys. Res. Commun. 43, 898-899.

13 Adam, W., Beinhauer, A., Epe, B., Fuchs, R., Griesbeck, A., Hauer, H., Mützel, P., Nassi, L., Schiffmann, D. and Wild, D. (1986) Genotoxic effects of 1,2-dioxetanes. In: T. Friedberg and F. Oesch (Eds.), Primary Changes and Control Factors in Carcinogenesis, Deutscher Fachschriften Verlag, Wiesbaden, pp. 64-67.

14 Epe, B., Mützel, P. and Adam, W. (1988) DNA damage by oxygen radicals and excited state species: a comparative study using enzymatic probes in vitro. Chem.-Biol. Interact. 69, 149-165.

15 Epe, B., Müller, E., Adam, W. and Saha-Möller, C.R. (1992) Photochemical DNA modifications induced by 1,2-dioxetanes. Chem.-Biol. Interact., in press.

16 Nassi, L., Epe, B., Schiffmann, D., Adam, W., Beinhauer, A. and Griesbeck, A. (1987) Induction of morphological transformation and micronuclei in Syrian hamster embryo fibroblasts by 1,2-dioxetanes. Correlation with single strand breaks in HL-60 cells. Carcinogenesis 8, 946-953.

17 Nassi, L., Schiffmann, D., Favre, A., Adam, W. and Fuchs, R. (1988) Induction of the SOS function sfiA in E. coli by systems which generate triplet ketones. Mutat. Res. 198, 53-60.

18 Adam, W., Albrecht, O., Feineis, E., Reuther, I., Saha-Möller, C.R., Seufert-Baumbach, P. and Wild, 
D. (1991) Benzofuran dioxetanes, a new class of mutagenic agents: synthesis by photooxygenation of benzofuran derivatives. Liebigs Ann. Chem. 33-40.

19 Adam, W., Hauer, H., Mosandl, T., Saha-Möller, C.R., Wagner, W. and Wild, D. (1990) Furocoumarin-, naphthofuran- and furoquinoline-annulated 1,2-dioxetanes: synthesis, thermolysis, and mutagenicity. Liebigs Ann. Chem. 1227-1236.

20 Adam, W., Hadjiarapoglou, L., Mosandl, T., Saha-Möller, C.R. and Wild, D. (1991) Synthesis of the 2,3-epoxy-2,3-dihydro-2,3-dimethylbenzo[b]furan, the proposed ultimate mutagen of the benzofuran dioxetanes. Angew. Chem. Int. Ed. Engl. 30, 201-202.

21 Adam, W., Hadjiarapoglou, L., Mosandl, T., Saha-Möller, C.R. and Wild, D. (1991) Chemical model studies on the mutagenesis of benzofuran dioxetanes in the Ames test: evidence for the benzofuran epoxide as ultimate mutagen. J. Am. Chem. Soc. 113, 8005-8011.

22 Adam, W., Bialas, J., Hadjiarapoglou, L. and Sauter, M. (1992) Epoxidation of 2,3-dimethylbenzofurans by dimethyldioxirane. Chem. Ber. 125, 231-234.

23 Gingerich, S.B. and Jennings, P.W. (1984) Mechanism for the $m$-chlorobenzoic acid oxidation of trialkyl-substituted furans. J. Org. Chem. 49, 1284-1286.

24 Gupta, R.C., Reddy, M.V. and Randerath, K. (1982) ${ }^{32}$ P-postlabelling analysis of non-radioactive aromatic carcinogen-DNA adducts. Carcinogenesis 3, 1081-1092.

25 Reddy, M.V. and Randerath, K. (1986) Nuclease Pl-mediated enhancement of sensitivity of ${ }^{32} \mathrm{P}$-postlabelling test for structurally diverse DNA adducts. Carcinogenesis 7, 1543-1551.

26 Phillips, D.H., Hewer, A. and Grover, P.L. (1986) Aromatic DNA adducts in human bone marrow and peripheral blood leukocytes. Carcinogenesis 7, 2071-2075.

27 Wild, D., Dirr, A., Fasshauer, I. and Henschler, D. (1989) Photolysis of arylazides and generation of highly electrophilic DNA-binding and mutagenic intermediates. Carcinogenesis 10, 335-341.

28 Adam, W. and Heil, M. (1992) Reaction of 1,2-dioxetanes with heteroatom nucleophiles: adduct formation by nucleophilic attack at the peroxide bond. J. Am. Chem. Soc. 114, 5591-5598.

29 Breimer, L.H. and Lindahl, T. (1984) DNA glycosylase activities for thymine residues damaged by ring saturation, fragmentation or ring contraction are functions of endonuclease III in Escherichia coli. J. Biol. Chem. 259, 5543-5548.

30 Breimer, L. (1984) Enzymatic excision from $\gamma$-irradiated poly-nucleotides of adenine residues whose imidazole rings have been ruptured. Nucleic Acids Res. 12, 6359-6367.

31 Tchou, J., Kasai, H., Shibutari, S., Chung, M.H., Laval, J., Grollman, A.P. and Nishimura, S. (1991) 8-Oxoguanine (8-hydroxyguanine) DNA glycosylase and its substrate specificity. Proc. Natl. Acad. Sci. USA $88,4690-4694$.

32 Boiteux, S., Gajewski, E., Laval, J. and Dizdaroglou, M. (1992) Substrate specificity of the Escherichia coli Fpg protein (formamidopyrimidine-DNA glycosylase): excision of purine lesions in DNA produced by ionizing radiation or photosensitization. Biochemistry 31, 106-110.

33 Kohn, K.W., Erickson, L.C., Erming, R.A.G. and Friedman, C.A. (1976) Fractionation of DNA from mammalian cells by alkaline elution. Biochemistry 15, 4629-4637.

34 Schiffmann, D. and De Boni, U. (1991) Dislocation of chromatin elementsin prophase induced by diethylstilbestrol: a novel mechanism by which micronuclei can arise. Mutat. Res. 246, 113-122.

35 Devasagayam, Th.P.A., Steenken, S., Obendorf, M.S.W., Schulz, W.A. and Sies, H. (1991) Formation of 8-hydroxy(deoxy)guanosine and generation of strand breaks at guanine residues by singlet oxygen. Biochemistry 30, 6283-6289.

36 Ravanat, J.-L., Berger, M., Bucho, G.W., Benard, J.-F., van Lier, J. and Cadet, J. (1992) Photooxidation sensibilisee de la deoxy-2'-guanosine par des phthalocyanines et naphthalocyanines. Determination de l'importance des mecanismes de types I et de type II. J. Chim. Phys. 88, 1069-1076. 